\title{
ASSESSMENT OF URBAN SOIL QUALITY IN MAJOR CITIES IN ROMANIA. CASE STUDIES
}

\author{
Bogdan Stanescu' ${ }^{1}$ Lidia Kim¹, Adriana Cuciureanu ${ }^{1}$,Carol Blaziu Lehr ${ }^{1}$ \\ ${ }^{1}$ National Research and Development Institute for Industrial Ecology, ECOIND, \\ Bucharest, 71-73 Drumul Podu Dambovitei street, district 6, 060652
}

\begin{abstract}
Studies conducted in major cities in Romania aimed to highlight the pollution of the topsoil cover in urban areas. Urban areas in Romania have suffered in the past two decades major changes, starting from the continued increase in urbanization, marked and development of urban infrastructure, the emergence of the new neighborhoods areas, commercial and residential areas, while reducing industrial activities or change of the industrial profile to commercial activities. A special importance is atributted to the increase of road traffic in urban areas and related issues linked to it, respectively fluency and pollution.

Programs, projects and measures that will be implemented in the coming years in urban areas in Romania, will experience a significant development that will result in an increase in the quality of life through an integrated approach to issues of the protection of the environment and protecting soils from urban areas. Evaluation of soil quality in urban areas toghether with a permanent monitoring creates prerequisites for a harmonious urban development based on protection of the natural resources.
\end{abstract}

Keywords: assessment, ecology, soil protection, urban soils

\section{Introduction}

The urban cities from Romania are characterized by a high degree of urbanization, extensive changes of the urban infrastructure, the growth of residential areas by the appearance of new districts and, not least by reducing of the industrial activities. Increasing of the urban infrastructure and the residential areas affecting the quality of urban environmental components, especially the soil covers. [1:4] Moreover, nonfunctionality in urban areas, such as heavy traffic in town, with a low fluency, also has a negative impact.[5] The ecological importance of the presence of heavy metals in urban soils is closely related to human health due to their high ecological transference reported as an indicator of urban environmental quality, however the severity of pollution depends not only on total heavy metal concentration of the soil, but also on the proportion of their mobile and bioavailable forms [6].

\section{Experimental}

In the first step is analyzed the current situation regarding the nature and pressures induced to the soil in urban areas by pollution, in the cities of lasi and Timisoara. This was accomplished through documentation in the field and taking samples of the soil in the two cities mentioned above and analyze soil samples (physico-chemical quality indicators) in laboratories of NRDI ECOIND Bucharest.

Evaluation and interpretation of results obtained in relation to the reference values established for the sensitive use of the soils, respectively Order 756/1997 for the approval of the Regulation on the assessment of environmental pollution as amended and supplemented. 
Field investigations for regarding of current soil pollution levels in cities lasi and Timisoara was conducted in May 2016, under an experimental field default. They were taken in total 61 soil samples from the surface edaphic layer (0-10 centimeters) and were analyzed in the laboratory for each soil sample, a numeber of 11 quality indicators. All testing methods used are standardized methods presented in Table 1. Analytical equipment used are of the most modern and for the soil sampling was used a pedological hand drill equipment produced by Eijkelkamp (Netherlands).

Table no.1 - Soil indicators and laboratory test methods

\begin{tabular}{|c|c|c|}
\hline No. & Quality indicators & Test methods \\
\hline 1 & $\mathrm{pH}$ & ISO 10390-2005 \\
\hline 2 & Dry matter & SR ISO 11465-1998 \\
\hline 3 & Humus & SR ISO 14235:2000 \\
& STAS 7184/21:1982 \\
\hline 4 & Kjeldahl nitrogen & SR ISO 11261-00 \\
\hline 5 & Sulphates & SR ISO 11048-99 \\
\hline 6 & Clorides & STAS 7184/7:1987 \\
& SR ISO 9297:2001 \\
\hline 7 & Iron & SR EN ISO 17294:2005 \\
\hline 8 & Lopper & SR EN ISO 17294:2005 \\
\hline 9 & Zinc & SR EN ISO 17294:2005 \\
\hline 10 & SR EN ISO 17294:2005 \\
\hline 11 & Total chromium & SR EN ISO 17294:2005 \\
\hline
\end{tabular}

A precise location is performed with a GPS receiver (Garmin, GPSMAP model 60Csx), the soil sampling areas in the cities of lasi and Timisoara is presented in Figures 1 and 2 , respectively a punctual maps of the soil samples.

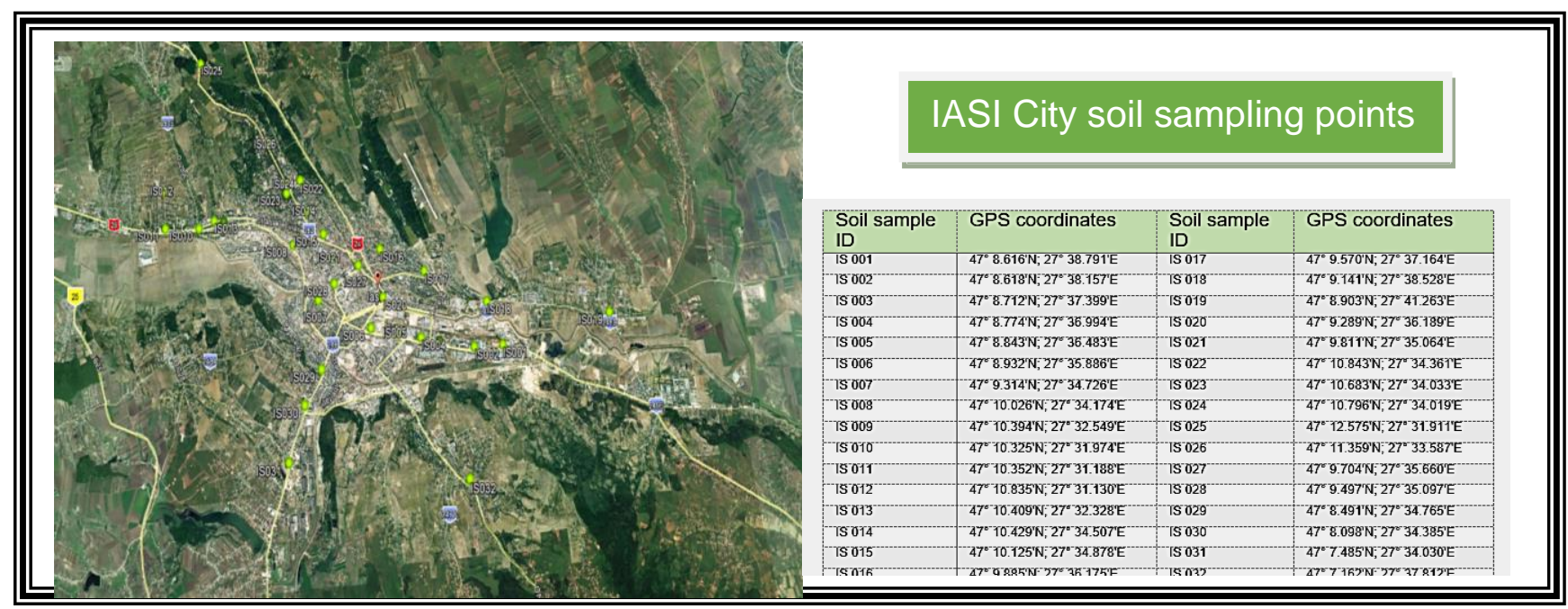

Figure 1 - Point map of sampling points in lasi City 


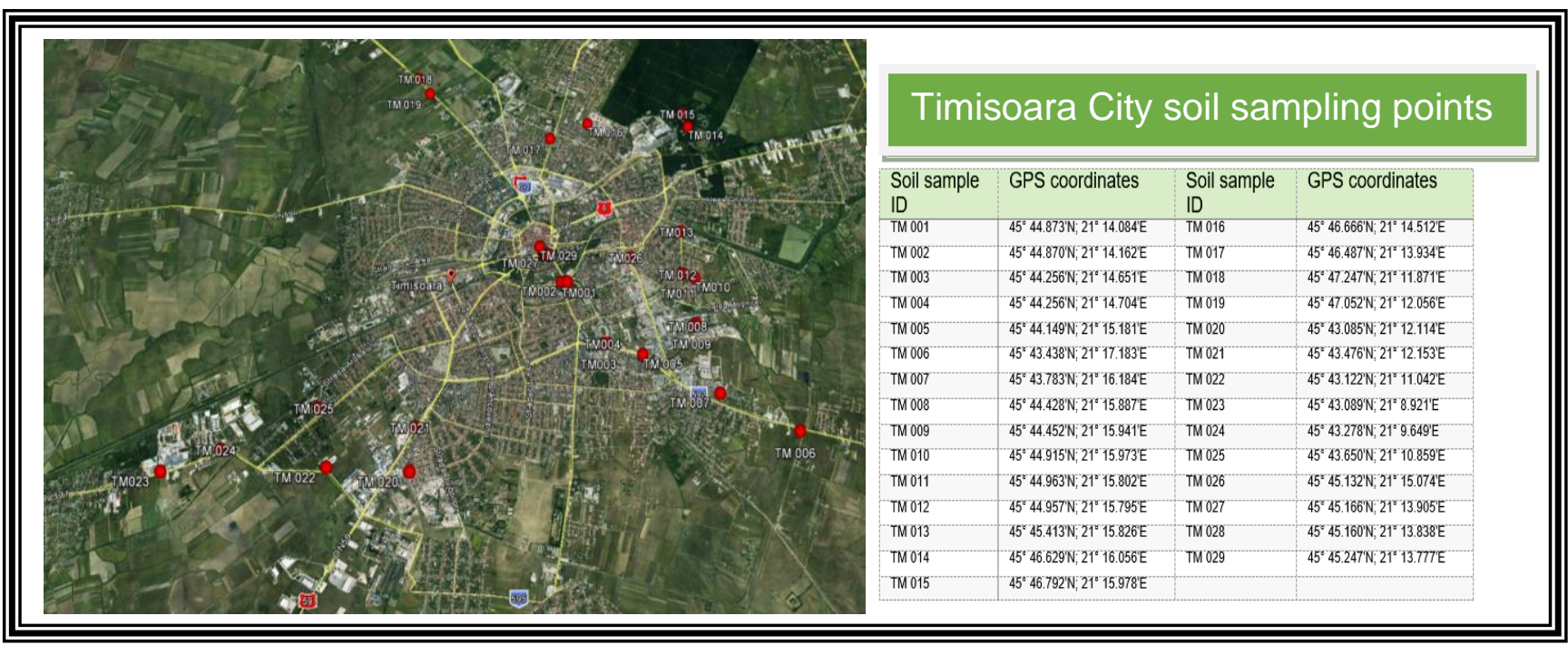

Figure 2 - Point map of sampling points in Timisoara City

\section{Results and Discussion}

The results obtained revealed a number of relevant issues related to heavy metal pollution issues presented in the following charts:

In Figures 3 and 4 are presented graphically variations of the quality indicator "Zinc" values, determined in soil samples related to cities lasi and Timisoara. This quality indicator is very important related to wide varying of the values recorded.

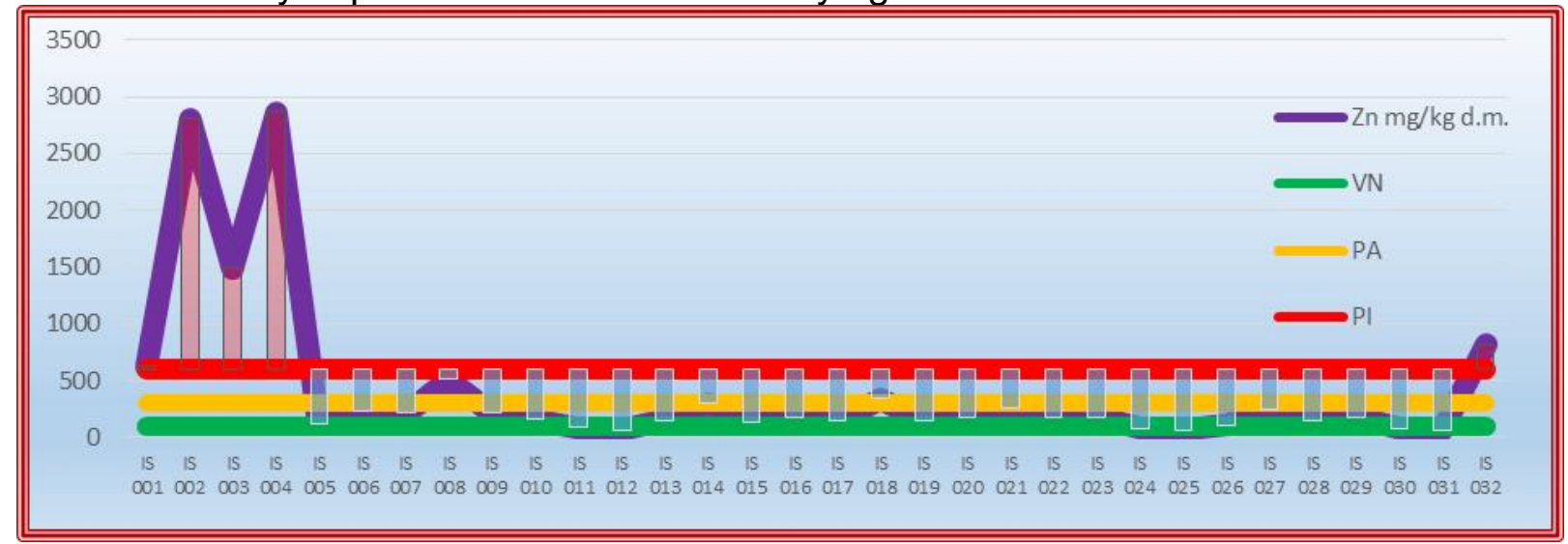

Fig.3 - Values of the quality indicator „Zinc” in soil samples from lasi City

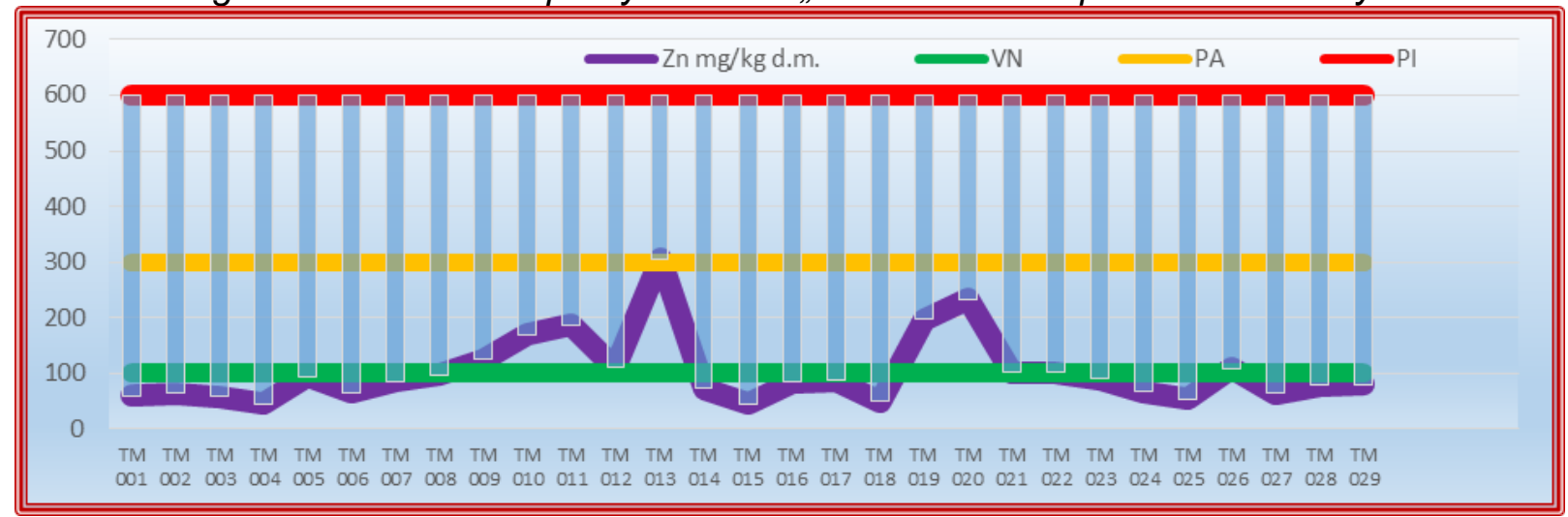

Fig. 4 - Values of the quality indicator „Zinc” in soil samples from Timisoara City 
Analyzing the values obtained for this indicator can highlight a few important conclusions:

- a significant pollution, historical, residual from time periods of intense activity of large economic units with industrial profile that function in lasi City, such as Tepro (Metalurgica), Combinatul de Utilaj Greu (Factory of Heavy Equipments) and Terom $\mathrm{SA}$; the pollution recorded is located in the industrial area of lasi and only a single case was registered at the soil sample taken from Bucium neighborhood, but not so far from the industrial area;

- the situation in Timisoara is different and positive in terms of pollution recorded, in one case values exceed the alert threshold level, a soil sample derived from proximity of the Old Water Plant Aquatim.

Figures 5 and 6 presents the graph varying of quality indicator "Copper" values determined in soil samples related to lasi and Timisoara Cities.

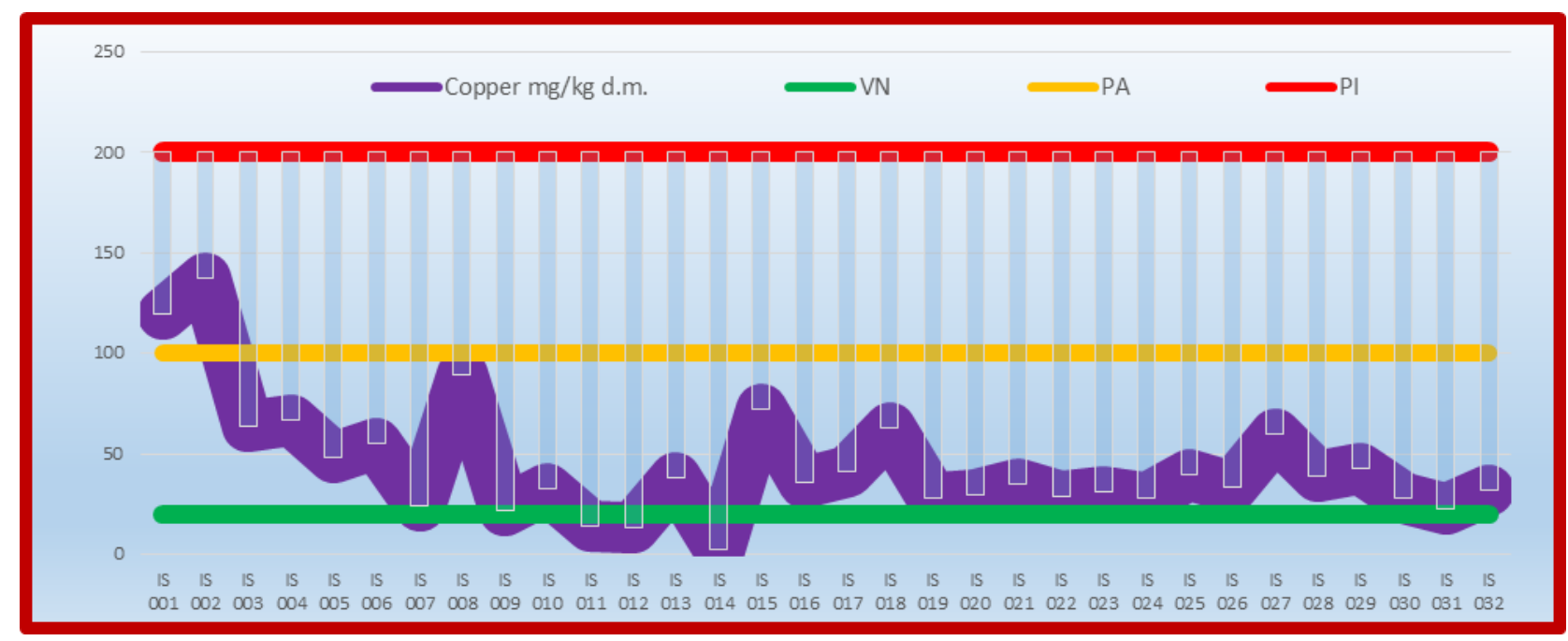

Fig.5 - Values of the quality indicator „Copper” in soil samples from lasi City

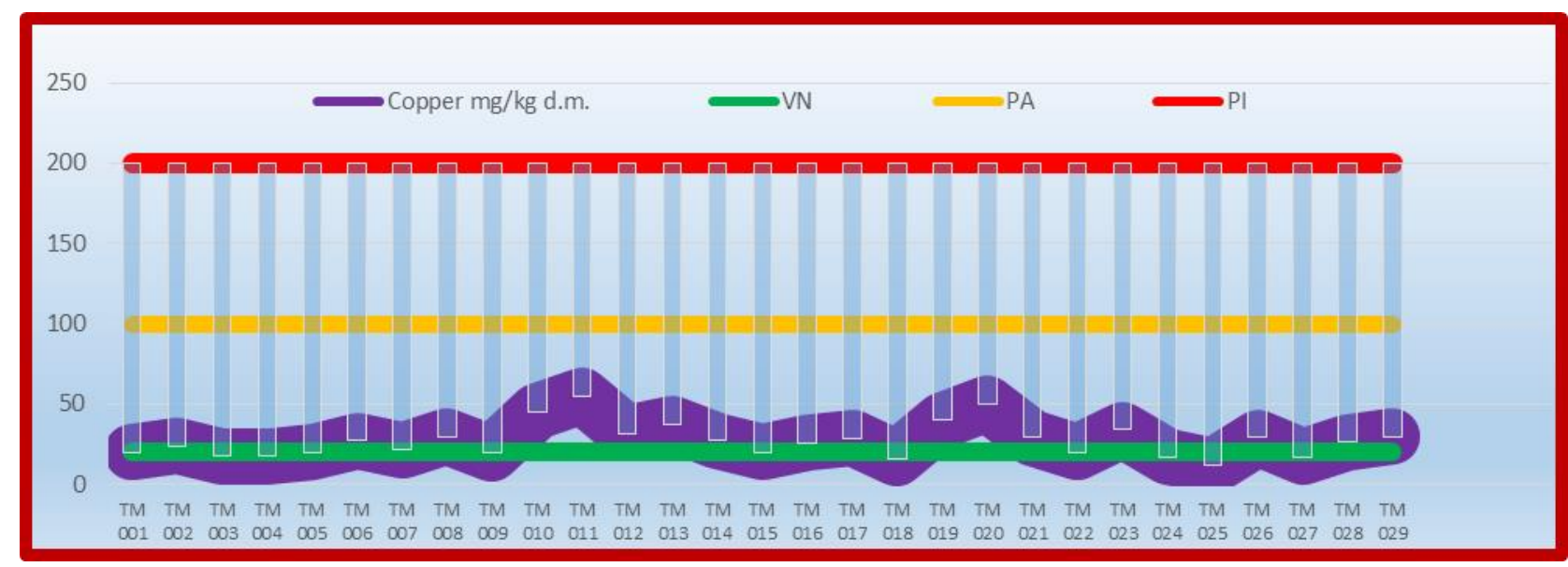

Fig.6 - Values of the quality indicator „Copper” in soil samples from Timisoara City

Analysis of the graphs that representing the values of the quality indicator "copper" highlights exceedances of alert levels in the industrial area of lasi and exceeding the normal range in most cases.

In Figures 7 and 8 are shown graphically variations of quality indicator "total chromium" values determined in soil samples related to lasi and Timisoara Cities. 


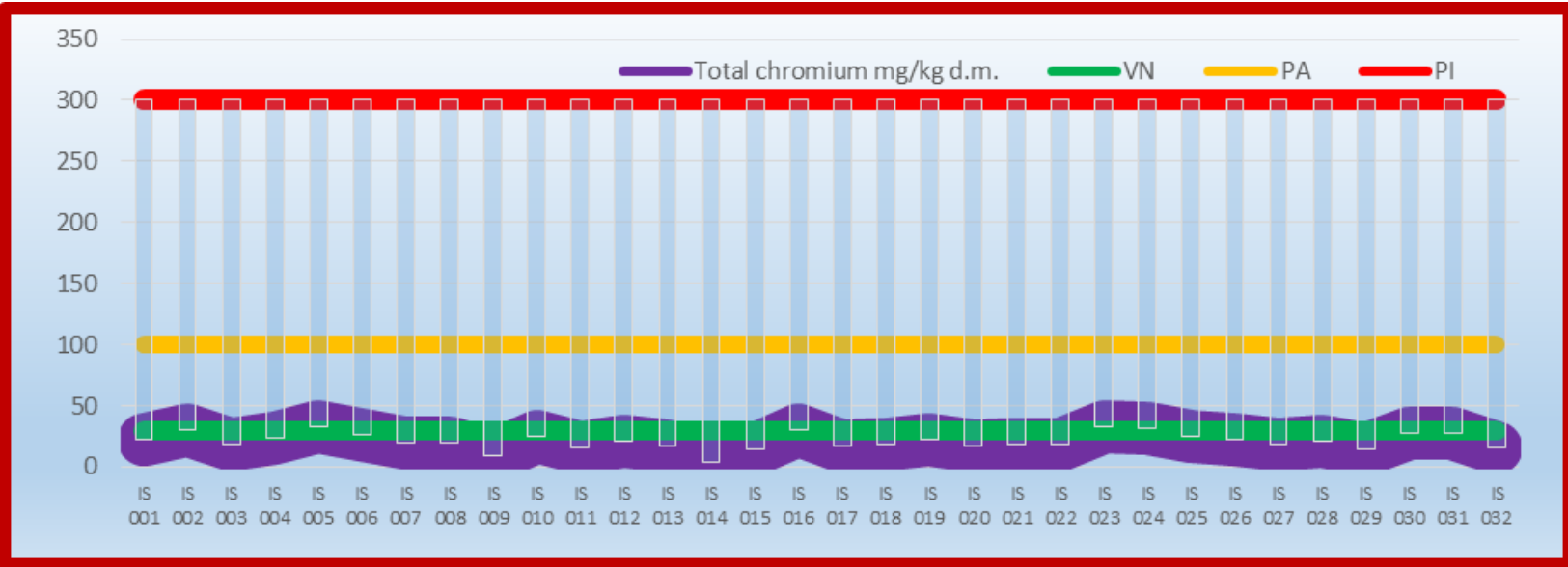

Fig.7 - Values of the quality indicator "Total Chromium” in soil samples from lasi City

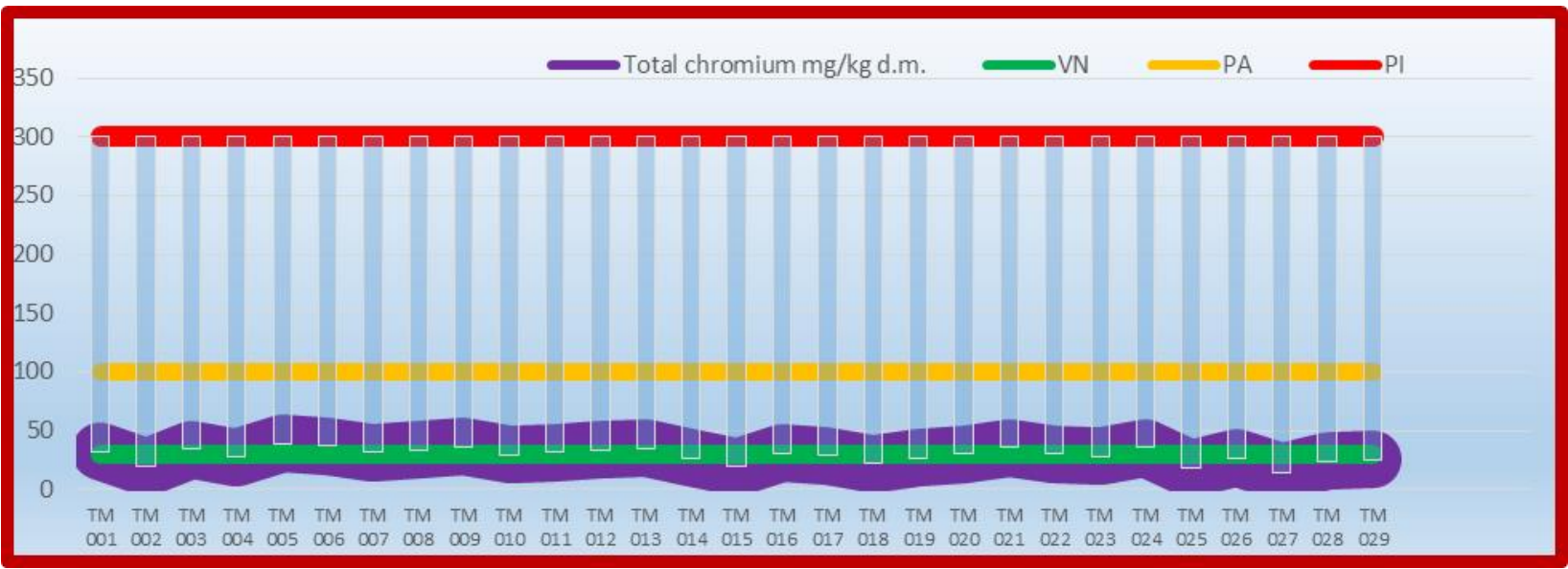

Fig.8 - Values of the quality indicator "Total Chromium” in soil samples from Timisoara City

Analyzing the quality indicator "Total chromium" values shows that are maintained around normal levels, with little value exceeding $30 \mathrm{mg} / \mathrm{kg}$ d.m.

In Figures 9 and 10 are shown graphically variations quality indicator "Lead" values determined in soil samples related to lasi and Timisoara Cities.

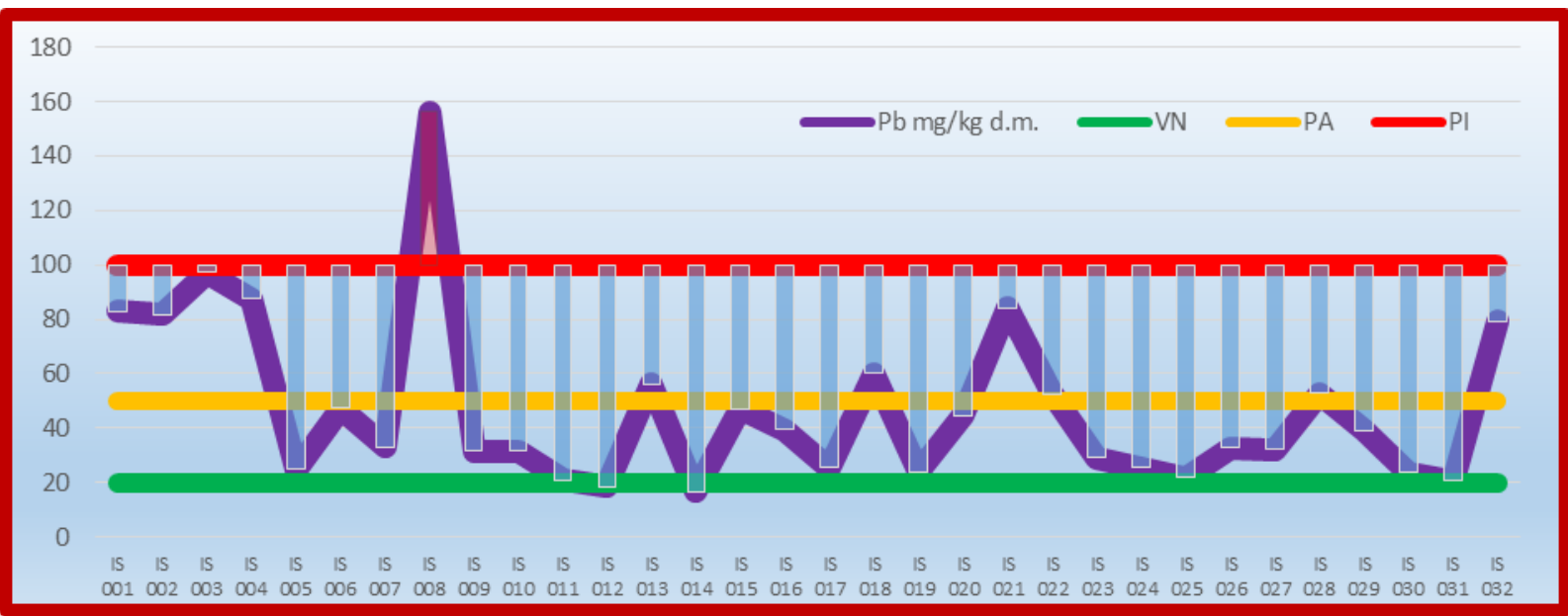

Fig.9 - Values of the quality indicator "Lead" in soil samples from lasi City 


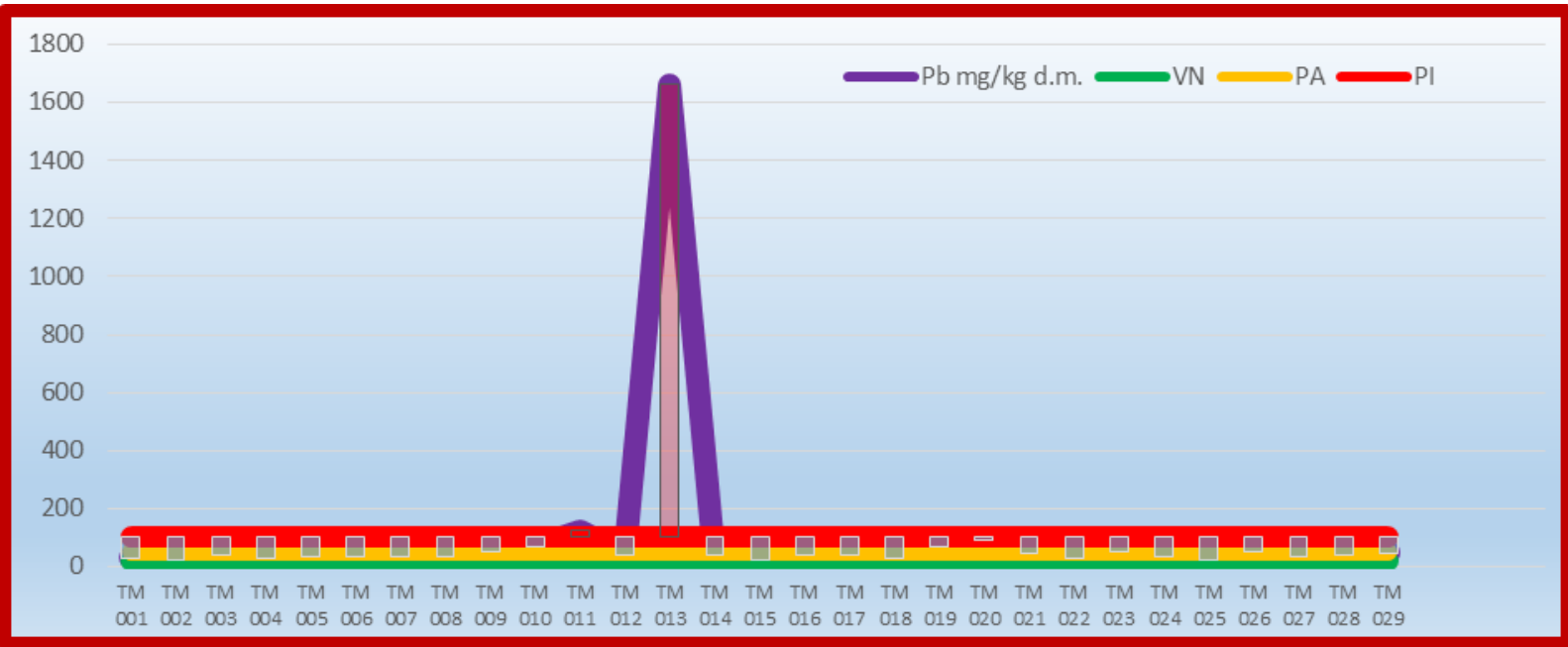

Fig.10 - Values of the quality indicator "Lead” in soil samples from Timisoara City

Analysis of the results obtained for the quality indicator "Lead" reveals some exceptional situations:

- in lasi City, soil samples taken in the vicinity of the Rails Station, an area with heavy traffic was recorded a value that exceeds the intervention threshold;

- in Timisoara City, intervention threshold is exceeded in two situations: the soil sample taken from Aquatim Old Plant area and Kunz area were is a uncontrolled deposition of waste on ground, directly to soil.

In terms of other quality indicators analyzed we identified:

- a pH values can highlight a neutral - slightly alkaline regime;

- a low amounts of organic matter (humus between $0.08 \div 1.48 \%$ in lasi and $0.11 \div$ $1.59 \%$ in Timisoara), a specific characteristic strong anthropogenic urban soils.

\section{Conclusions}

Overall it can highlight a number of conclusions on the current state of soil pollution in both cities analyzed:

- a strong footprint of the industrial activities carried out in lasi, highlighted by heavy metal pollution, induced mainly by the quality indicator values obtained for "zinc".

Here it should be noted as important a industrial profile (metallurgical) of lasi City who has held numerous sources of air pollution that have polluted the soil cover by dispersing of the pollutants.

- in Timisoara City is note worthy both economic specifics with more diversified and geographic location dispersed of the industrial activities in the city, not concentrated in a limited area, such find in lasi City.

\section{Acknowledgements}

Research activities were developed in the frame of the "Nucleu Programme”, project PN 162502 06, „URBASOL” with title „Study of the urban soil pollution levels in main cities in Romania" 


\section{References}

[1] United Nations (2010) World Urbanization Prospects The 2009 Revision, Highlights, United Nations;

[2] Seto, K.C. et al. (2010) The new geography of contemporary urbanization and the Environment. Annu. Rev Environ. Resources 35, 167-194

[3] McDonald, T.I. et al 2008 The implications of curent and future urbanization for global protected areas and biodiversity conservation., Biol Conserv, 141, 1695-1703

[4] Theobald, D.M. (2004) Placing exurban land-use change in a human modification framework, Front. Ecol. Environ.2, 139-144

[5] M.Dumitru, A. Manea, C. Ciobanu, S. Dumitru, N. Vrinceanu, I. Calciu, V. Tanase, M. Preda, I. Rasnoveanu, V. Mocanu, M. Eftene, „Monitoringul starii de calitate a solurilor din Romania”, Ed. Sitech, Craiova, 2011;

[6] Celestin Defo et al, (2015), Assessment of heavy metals in soils ang groundwater in an urban watershed of Yaounde (Cameroon-West Africa), Environ Monit Assess 187. 